\author{
Military Technical College \\ Kobry Elkobbah, \\ Cairo, Egypt
}

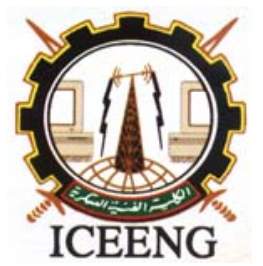

\author{
$5^{\text {th }}$ International Conference \\ on Electrical Engineering \\ ICEENG 2006
}

\title{
A Binary Particle Swarm Optimization for Optimal Placement and Sizing of Capacitor Banks in Radial Distribution Feeders with Distorted Substation Voltages
}

\author{
Tamer Mohamed Khalil ${ }^{*}$, Hosam K.M. Youssef ${ }^{* *}$, Member, IEEE, M.M. Abdel Aziz ${ }^{* * *}$, \\ Senior Member, IEEE
}

\begin{abstract}
This paper proposes a binary particle swarm optimization (PSO) for optimal placement and sizing of fixed capacitor banks in radial distribution lines with nonsinusoidal substation voltages. The objective function includes the cost of power losses and capacitor banks with constraints which include limits on voltage, total harmonic distortion (THD) and sizes of installed capacitors. A binary PSO applied to a test system and solutions of the binary PSO are compared with those of heuristic numerical algorithm that is based on the method of local variations. Computer simulation shows that the harmonic components affect the optimal capacitor placement and sizing.
\end{abstract}

\section{KEY WORDS}

Capacitor placement, binary particle swarm optimization, harmonics, power flow, capacitor sizing.

\section{NOMENCLATURE}

$P_{\text {loss }(i, i+1)}^{1}, P_{\text {loss }}$ the power losses at power frequency and the total power losses.

$V_{i}^{1} \quad$ the fundamental voltage at bus $i$.

$y_{l i}^{h} \quad$ the $h$-th harmonic frequency load admittances.

$P_{l i}, Q_{l i} \quad$ load active and reactive powers at bus $i$.

$y_{c i}^{h}, y_{i, i+1}^{h} \quad$ the $h$-th harmonic frequency capacitor admittances and feeder admittances.

$R_{i, i+1}, X_{i, i+1} \quad$ resistance and inductive reactance of feeder section between buses $i$ and $i+1$.

$H \quad$ the upper limit of considered harmonic order.

$Q_{0}^{c}, Q_{\max }^{c} \quad$ smallest capacitor size and the maximum allowable capacitor size to be placed.

$L \quad$ an integer.

$Q_{j}^{c} \quad$ the shunt capacitor size placed at bus $j$.

F the total annual cost function.

* Canal Co. for Electricity Distribution, Ismailia, Egypt

${ }^{* *}$ Electric power and machine Dept., Faculty of Engineering, Cairo University .Egypt. 


$$
\begin{array}{ll}
K^{p}, K_{j}^{c} & \text { the cost per unit of power losses and the capacitor annual cost/kvar. } \\
V_{\min }, V_{\max } & \text { minimum and maximum permissible rms voltage } \\
J, m & \text { shunt capacitor buses and number of buses. }
\end{array}
$$

\section{INTRODUCTION}

Power distribution from electric power plants to ultimate consumers is accomplished via the transmission sub transmission, and distribution lines. Studies have indicated that as much as $13 \%$ of total power generated is consumed as $I^{2} R$ losses at the distribution level [1]. The $I^{2} R$ losses can be separated to active and reactive component of branch current, where the losses produced by reactive current can be reduced by the installation of shunt capacitors. Capacitors are widely used in distribution systems to reduce energy and peak demand losses, release the $\mathrm{kVA}$ capacities of distribution apparatus and to maintain a voltage profile within permissible limits. The objective of optimal capacitor placement problem is to determine the size, type, and location of capacitor banks to be installed on radial distribution feeders to achieve positive economic response. The economic benefits obtained from the loss reduction weighted against capacitors costs while keeping the operational and power quality constraints within required limits.

Most of the capacitor placement techniques assume sinusoidal conditions and ignore the effect of harmonics [2]-[18]. Limited publications have taken into consideration the presence of harmonics when solving the capacitor placement problems [19]-[27]. Capacitor significantly influences the propagation of system harmonics, and could cause parallel resonance. Therefore, the optimal selection and placement of capacitor banks must be integrated with the estimation of harmonic levels.

A new evolutionary computation technique, called particle swarm optimization (PSO), has been proposed and presented recently [28]-[39]. This technique has been developed through the simulation of simplified social models [28], and has been found to be robust in solving continuous nonlinear optimization. Moreover Kennedy and Eberhart [39] have adapted the PSO to search in binary spaces. Therefore the method can be expanded to solve nonlinear optimization problems with both equality and inequality constraints [32]-[35].

Recently, PSO have been successfully applied to various fields of power system optimization such as reactive power and voltage control [36], power system stabilizer design [37] and reactive power dispatch [38].

In this paper a binary PSO algorithm applied to a test system shown in [19] with the same formulation, assumption and constraints for optimizing shunt capacitor sizes at a candidate buses (4, 5 and 9) on radial distribution lines with nonsinusoidal substation voltages to compare it with that obtained in [19]. Then the same binary PSO algorithm applied to the same test system to find optimal placement and sizing of shunt capacitor (apply the binary PSO algorithm to all the buses).

\section{SYSTEM MODEL AT FUNDAMENTAL AND HARMONIC FREQUENCIES}

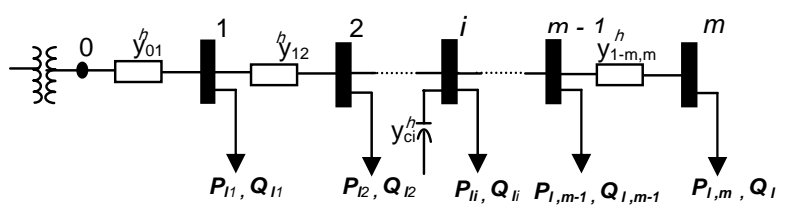

Fig. 1: One-line Diagram of radial Distribution feeder 
For modeling of a distribution system Fig.1 at fundamental and harmonic frequencies the formulation and notations and assumption of [19] are used. A review of harmonic load flow found in [40] and computer modeling and analysis of power systems harmonics found in [41]. The modeling steps are as follows:

- Calculate the magnitudes and the phase angles of the bus voltages at fundamental frequency by using Newton-Raphson power flow method and calculate the power losses at the power frequency Eqn. (1).

- Calculate the h-th harmonic frequency load admittances, shunt capacitor admittances and feeder admittances Eqns. (2)-(4) respectively.

- Calculate the harmonic voltages [19], the rms voltage and the total harmonic distortion from Eqns. (5)-(7) respectively.

$$
\begin{aligned}
& P_{\text {loss }(i, i+1)}^{1}=R_{i, i+1}\left[\left|V_{i+1}^{1}-V_{i}^{1} \| y_{i, i+1}^{1}\right|\right]^{2} \\
& y_{l i}^{h}=\frac{P_{l i}}{\left|V_{i}^{1}\right|}-j \frac{Q_{l i}}{h\left|V_{i}^{1}\right|^{2}} \\
& y_{c i}^{h}=h y_{c i}^{1} \\
& y_{i, i+1}^{h}=\left(R_{i, i+1}+j h X_{i, i+1}\right)^{-1} \\
& {\left[\begin{array}{llll}
Y_{11}^{h} & Y_{11}^{h} & 0 & 0 \\
Y_{11}^{h} & Y_{11}^{h} & \cdot & \\
0 & \cdot & \cdot & \\
\cdot & \cdot & \cdot & 0 \\
\cdot & \cdot & Y_{m-1, m-1}^{h} & Y_{m-1, m}^{h} \\
0 & 0 & Y_{m, m-1}^{h} & Y_{m, m}^{h}
\end{array}\right]\left[\begin{array}{c}
V_{1}^{h} \\
V_{2}^{h} \\
\cdot \\
V_{m-1}^{h} \\
V_{m}^{h}
\end{array}\right]=\left[\begin{array}{c}
y_{01}^{h} V_{0}^{h} \\
0 \\
\cdot \\
\cdot \\
0 \\
0
\end{array}\right]} \\
& \left|V_{i}\right|=\sqrt{\sum_{h=1}^{H}\left|V_{i}^{h}\right|^{2}} \\
& T H D_{i}(\%)=\frac{100}{\left|V_{i}^{1}\right|} \sqrt{\sum_{h \neq 1}^{H}\left|V_{i}^{h}\right|^{2}}
\end{aligned}
$$

\section{PROBLEM FORMULATION}

The objective function Eqn. (10) is to minimize the total annual cost due to capacitor placement and power losses with constraints that include limits on voltage Eqn. (12), total harmonic distortion Eqn. (11) and size of installed capacitors Eqn. (9).

$$
\begin{aligned}
& P_{\text {loss }}=\sum_{h=1}^{H}\left(\sum_{i=0}^{m-1} P_{\text {loss }(i, i+1)}^{h}\right) \\
& Q_{\max }^{c}=L Q_{0}^{c} \\
& F=K^{p} P_{\text {loss }}+\sum_{j=1}^{J} K_{j}^{c} Q_{j}^{c} \\
& T H D_{i} \leq T H D_{\max } \\
& V_{\min } \leq\left|V_{i}\right| \leq V_{\max }
\end{aligned}
$$




\section{PARTICLE SWARM OPTIMIZATION}

Particle Swarm Optimization is an algorithm developed by Kennedy and Eberhart [28] that simulates the social behaviors of bird flocking or fish schooling and the methods by which they find roosting places, foods sources or other suitable habitat.

In the basic PSO technique, suppose that the search space is d-dimensional,

- Each member is called particle, and each particle (i-th particle) is represented by ddimensional vector and described as $X_{i}=\left[x_{i 1}, x_{i 2}, \ldots \ldots, x_{i d}\right]$.

- The set of $\mathrm{n}$ particle in the swarm are called population and described as pop $=\left[X_{1}\right.$, $\left.X_{2}, \ldots, X_{n}\right]$.

- The best previous position for each particle (the position giving the best fitness value) is called particle best and described as $P B_{i}=\left[p b_{i 1}, p b_{i 2}, \ldots, p b_{i d}\right]$.

- The best position among all of the particle best position achieved so far is called global best and described as $G B=\left[g b_{1}, g b_{2}, \ldots . ., g b_{d}\right]$.

- The rate of position change for each particle is called the particle velocity and described as

$$
V_{i}=\left[v_{i 1}, v_{i 2}, \ldots \ldots, v_{i d}\right] \text {. }
$$

At iteration $k$ the velocity for d-dimension of i-particle is updated by:

$$
v_{i d}^{k+1}=w v_{i d}^{k}+c_{1} r_{1}\left(p b_{d}^{k}-x_{i d}^{k}\right)+c_{2} r_{2}\left(g b_{d}^{k}-x_{i d}^{k}\right)
$$

Where $\mathrm{i}=1,2, . ., \mathrm{n}$ and $\mathrm{n}$ is the size of population, $\mathrm{w}$ is the inertia weight, $c_{1}$ and $c_{2}$ are the acceleration constants, and $r_{1}$ and $r_{2}$ are two random values in range [0,1]. The optimal selection of the previous parameters found in [29]-[30].

- The i-particle position is updated by

$$
x_{i d}^{k+1}=x_{i d}^{k}+v_{i d}^{k+1}
$$

For binary discrete search space, Kennedy and Eberhart [39] have adapted the PSO to search in binary spaces, by applying a sigmoid transformation to the velocity component Eqn. (15) to squash the velocities into a range [0,1], and force the component values of the locations of particles to be 0's or 1's. The equation for updating positions Eqn. (14) is then replaced by Eqn. (16).

$$
\begin{gathered}
\operatorname{sigmoid}\left(v_{i d}^{k}\right)=\frac{1}{1+e^{-v_{i d}^{k}}} \\
x_{i d}^{k}=\left\{\begin{array}{lc}
1, \text { if rand }<\text { sigmoid }\left(v_{i d}^{k}\right) \\
0, & \text { otherwise }
\end{array}\right.
\end{gathered}
$$

The PSO technique can be expressed as follow:

Step 1) (Initialization): Set the iteration number $\mathrm{k}=0$. Generate randomly $\mathrm{n}$ particles, $\left\{X^{0}{ }_{i}, \mathrm{i}=\right.$ $1,2, \ldots, \mathrm{n}\}$, where $X_{i}^{0}=\left[x^{0}{ }_{i 1}, X^{0}{ }_{i 2, \ldots \ldots, X^{0}}{ }_{i d}\right]$, and their initial velocities $V_{i}^{0}=\left[v^{0}{ }_{i 1}\right.$, $\left.v^{0}{ }_{i 2}, \ldots . ., v_{i d}^{0}\right]$. Evaluate the objective function for each particle $f\left(X^{0}{ }_{i}\right)$. If the constraints are satisfied, then set the particle best $P B^{0}{ }_{i}=X^{0}{ }_{i}$, and set the particle best which give the best objective function among all the particle bests to global best GB ${ }^{0}$. Else, repeat the initialization.

Step 2) Update iteration counter $\mathrm{k}=\mathrm{k}+1$

Step 3) Update velocity using Eqn. (13).

Step 4) Update position using the sigmoid function Eqn. (15) and Eqn. (16).

Step 5) Update particle best: 


$$
\text { If } f_{i}\left(X_{i}^{k}\right)<f_{i}\left(P B_{i}^{k-1}\right) \text { then } P B_{i}^{k}=X_{i}^{k} \text { else } P B_{i}^{k}=P B_{i}^{k-1}
$$

Step 6) Update global best: $f\left(G B^{k}\right)=\min \left\{f_{i}\left(P B_{i}^{k}\right)\right\}$

If $f\left(G B^{k}\right)<f\left(G B^{k-1}\right)$ then $G B^{k}=G B^{k}$ else $G B^{k}=G B^{k-1}$

Step 7) Stopping criterion: If the number of iteration exceeds the maximum number iteration, then stop, otherwise go to step 2.

\section{Formulation of Capacitor Placement Using Binary PSO}

The system shown in Fig. 1 is $m$-bus radial distribution system. Table 1 shows a sample of the yearly cost of fixed capacitor sizes. To select the capacitor size $Q_{j}^{c}$ to be placed at bus $j$, a combination of capacitor sizes (R-size) is chosen from Table 1, as an example,

$$
Q^{c}{ }_{j}=\left(b_{1} s Z_{1}+b_{2} S Z_{2}+\ldots+b_{r} S Z_{r}+\ldots+b_{R} S Z_{R}\right)
$$

\section{Where:}

$j \in J$, $J$ is a set of candidate buses to capacitors placement

$b_{r}=\{0,1\}$.

$S Z_{r}$ : capacitor size from Table $I$.

$Q_{j}^{c} \leq Q_{\text {max }}^{c}, Q_{\text {max: }}^{c}$ the maximum allowable capacitor size to be placed at any bus.

\section{For optimal capacitor placement a binary PSO will be used as follows:}

- The capacitor $Q_{j}^{c}$ which will be placed at candidate bus $j$ consists of small capacitor sizes ( $R$-size) Eqn.(17), where The candidate buses are $J$-bus,

- A population of $n$ particles at iteration $k$ is represented by: $p o p^{k}=\left[X^{k}{ }_{1}, X^{k}{ }_{2}, \ldots, X^{k}{ }_{i}, \ldots, X_{n}^{k}\right]$,

- Each particle $i$ represented in $J$-dimensional ( $J$ represents the candidate buses ) by: $X^{k}{ }_{i}=$ $\left[x^{k}{ }_{i 1}, x^{k}{ }_{i 2}, \ldots, x^{k}{ }_{i j}, \ldots, x^{k}{ }_{i J}\right]$,

Each dimension $j$ represented in $R$-dimensional ( $R$ represents the number of capacitor sizes to choose from) by: $x^{k}{ }_{i j}=\left[x_{i j 1}^{k}, x^{k}{ }_{i j 2}, \ldots x^{k}{ }_{i j r}, \ldots x^{k}{ }_{i j R}\right]$

therefore, each particle $i$ represented in $(J, R)$ dimensions by:

$$
X_{i}^{k}=\left[\begin{array}{cccccc}
x_{i 11}^{k} & x_{i 12}^{k} & \ldots & x_{i 1 r}^{k} & \ldots & x_{i 1 R}^{k} \\
x_{i 21}^{k} & x_{i 22}^{k} & \ldots & x_{i 2 r}^{k} & \ldots & x_{i 2 R}^{k} \\
\cdot & . & \ldots & & \ldots & . \\
x_{i j 1}^{k} & x_{i j 2}^{k} & \ldots & x_{i j r}^{k} & \ldots & x_{i j R}^{k} \\
\cdot & . & \ldots & & \ldots & \cdot \\
x_{i J 1}^{k} & x_{i J 2}^{k} & \ldots & x_{i J r}^{k} & \ldots & x_{i J R}^{k}
\end{array}\right]
$$

- The capacitor size at bus $j$ at iteration $k$ in particle $i$ represented by :

$$
Q_{i j}^{c(k)}=x^{k}{ }_{i j 1} S Z_{1}+x_{i j 2}^{k} S Z_{2}+\ldots+x_{i j r}^{k} S Z_{r}+\ldots+x^{k}{ }_{i j R} S Z_{R}
$$

- The dimension $x^{k}{ }_{i j r}$ indicates if the capacitor size $s z_{r}$ is placed at bus $j$ at iteration $k$ in particle $i$ or not. In other words, $x_{i j r}^{k}$ is a binary value such that $x_{i j r}^{k}=1$ if the capacitor size $S Z_{r}$ is placed at bus $j$ at iteration $k$ in particle $i, x_{i j r}^{k}=0$ if it is not placed.

- The particle best, global best and the particle velocity are represented also in $(J, R)$ dimensions.

\section{NUMERICAL EXAMPLE}


The proposed binary PSO were applied to the test system described in [19] and the results were compared to that's obtained in [19] using a simple heuristic numerical algorithm that is based on the method of local variations. The load and the feeder data are listed in Table 2 and Table 3 respectively. It is desired to find:

(1) The optimal values of capacitor sizes to be placed at buses 4, 5, and 9 .

(2) The optimal placement and sizing of capacitors (apply binary PSO to all the 9 buses).

Kp was selected to be $168 \$ / \mathrm{kW}$, and the voltage limits on the rms voltages were selected as $\mathrm{Vmin}=0.9 \mathrm{pu}$, and $\mathrm{Vmax}=1.1 \mathrm{pu}$. It was assumed that the substation voltage contains $4 \%$ and $3 \%$ of 5-th and 7-th harmonic, respec-tively, resulting in a total harmonic distortion of 5\%.

Commercially-available capacitor sizes with real costs/kvar were used in the analysis. It was decided that the largest capacitor size $Q^{c}{ }_{\max }$ should not exceed the total reactive load, i.e., 4186 kvar. The yearly costs of capacitor sizes [19] are shown in Table 1.

Optimum shunt capacitor sizes have been evaluated for the following cases: (a) the harmonic frequencies are ignored, (b) the harmonic frequencies are taken into account, but no limit is imposed on the total harmonic distortion, (c) the higher frequency components are taken into account, but limits are imposed on the total harmonic distortion. Two limits were selected: (i) THDmax $=8 \%$, and (ii)THDmax $=5 \%$.

The parameters used through the simulation are as follows:

$n=20$ particles, $w=0.8, c_{1}=c_{2}=2$,

$R=7$ sizes, $s z_{1}=150,{s z_{2}}_{2}=300, \ldots \ldots ., s_{7}=1050$.

$J=3$ for buses $\{4,5,9\}$, and $J=9$ for all the buses.

TABLE 1

YEARLY COST OF FIXED CAPACITORS [19]

\begin{tabular}{||c|c|c|c|c|c|c|c||}
\hline \hline & 1 & 2 & 3 & 4 & 5 & 6 & 7 \\
Capacitor size (kvar) & 150 & 300 & 450 & 600 & 750 & 900 & 1050 \\
Capacitor cost (\$/kvar) & 0.5 & 0.35 & 0.253 & 0.22 & 0.276 & 0.183 & 0.228 \\
\hline \hline & 8 & 9 & 10 & 11 & 12 & 13 & 14 \\
Capacitor size (kvar) & 1200 & 1350 & 1500 & 1650 & 1800 & 1950 & 2100 \\
Capacitor cost (\$/kvar) & 0.17 & 0.207 & 0.201 & 0.193 & 0.187 & 0.211 & 0.176 \\
\hline \hline & 15 & 16 & 17 & 18 & 19 & 20 & 21 \\
Capacitor size (kvar) & 2250 & 2400 & 2550 & 2700 & 2850 & 3000 & 3150 \\
Capacitor cost (\$/kvar) & 0.197 & 0.17 & 0.189 & 0.187 & 0.183 & 0.18 & 0.195 \\
\hline \hline & 22 & 23 & 24 & 25 & 26 & 27 & \\
Capacitor size (kvar) & 3300 & 3450 & 3600 & 3750 & 3900 & 4050 & \multicolumn{5}{|l|}{} \\
Capacitor cost (\$/kvar) & 0.174 & 0.188 & 0.17 & 0.183 & 0.182 & 0.179 \\
\hline
\end{tabular}

TABLE 2

3-PHASE LOAD DATA
\begin{tabular}{||c|c|c|}
\hline $\begin{array}{c}\text { BuS } \\
\#\end{array}$ & $\mathrm{P}(\mathrm{kW})$ & $\mathrm{Q}(\mathrm{kvar})$ \\
\hline \hline 1 & 1840 & 460 \\
\hline 2 & 980 & 340 \\
\hline 3 & 1790 & 446 \\
\hline 4 & 1598 & 1840 \\
\hline 5 & 1610 & 600 \\
\hline 6 & 780 & 110 \\
\hline 7 & 1150 & 60 \\
\hline 8 & 980 & 130 \\
\hline 9 & 1640 & 200 \\
\hline
\end{tabular}

TABLE 3 FEEDER DATA AT $60 \mathrm{HZ}$

\begin{tabular}{||c|c|c|c||}
\hline \hline Bus\# i & Bus\# i+1 & Ri,i+1 $(\Omega)$ & Xi,i+1 $(\Omega)$ \\
\hline \hline 0 & 1 & 0.1233 & 0.4127 \\
\hline 1 & 2 & 0.014 & 0.6051 \\
\hline 2 & 3 & 0.7463 & 1.205 \\
\hline 3 & 4 & 0.6984 & 0.6084 \\
\hline 4 & 5 & 1.9831 & 1.7276 \\
\hline 5 & 6 & 0.9053 & 0.7886 \\
\hline 6 & 7 & 2.0552 & 1.164 \\
\hline 7 & 8 & 4.7953 & 2.716 \\
\hline 8 & 9 & 5.3434 & 3.0264 \\
\hline \hline
\end{tabular}

\section{The simulation results showed in Table 4 clear that:}

- Before shunt capacitor placement, the annual costs function equal to \$131675 due to the total power losses of $783.3 \mathrm{~kW}$. The minimum rms voltage was $0.383 \mathrm{Pu}$, and the maximum THD was $4.9 \%$.

- Case (a) when the THD are ignored, applying the heuristic optimization (H.O.) at a candidate buses [4, 5 and 9] shows a yearly benefits of $\$ 12167$ and max.THD of $11.2 \%$, applying a binary PSO at the same candidate buses [4, 5 and 9] shows an increasing in yearly benefits to $\$ 12979$ and max.THD of $12 \%$, applying a binary PSO to optimal capacitor placement and sizing shows the best benefits \$15907 and max.THD of $12.75 \%$.

- Case (b) when the THD are taken into account but without limits, the benefits and the max.THD of H.O., a binary PSO at a candidate buses and a binary PSO at all buses are (\$12939, 10.8\%), (\$14588,11.9\%), and (\$16506, 13.4\%), respectively. Note that the benefits in case (b) are better than that in case (a) this is due to the effect of the harmonic frequencies which increase the rms voltages. Thus, less kvars are needed to bring the voltage levels up to the minimum permissible level. 
- Case (c) when the THD are taken into account with limits of (i) max.THD $=8 \%$ (ii) max.THD $=5 \%$, the benefits and the THD of H.O., a binary PSO at a candidate buses and a binary PSO at all buses in (i) and (ii) are (i) $(\$ 5511,7.96 \%),(\$ 6713,7.95 \%)$ and $(\$ 6735$, 7.99\%), respectively (ii) (\$-7410, 5\%), (\$-5856, 4.95\%) and (\$-5856, 4.95\%), respectively. In case (chi) the benefits are negative to control the max.THD and the rms voltages to acceptable levels.

- In all cases optimization of the system by a binary PSO algorithm at a candidate buses indicates yearly benefit better than that indicates by heuristic algorithm at the same candidate buses, and the optimal placement and sizing (apply the algorithm to all the 9 buses) using binary PSO indicate the best benefits.

TABLE 4

OPTIMAL SOLUTIONS FOR DIFFERENT CASES USING HEURISTIC ALGORITHM [19] AND BINARY PSO ALGORITHM

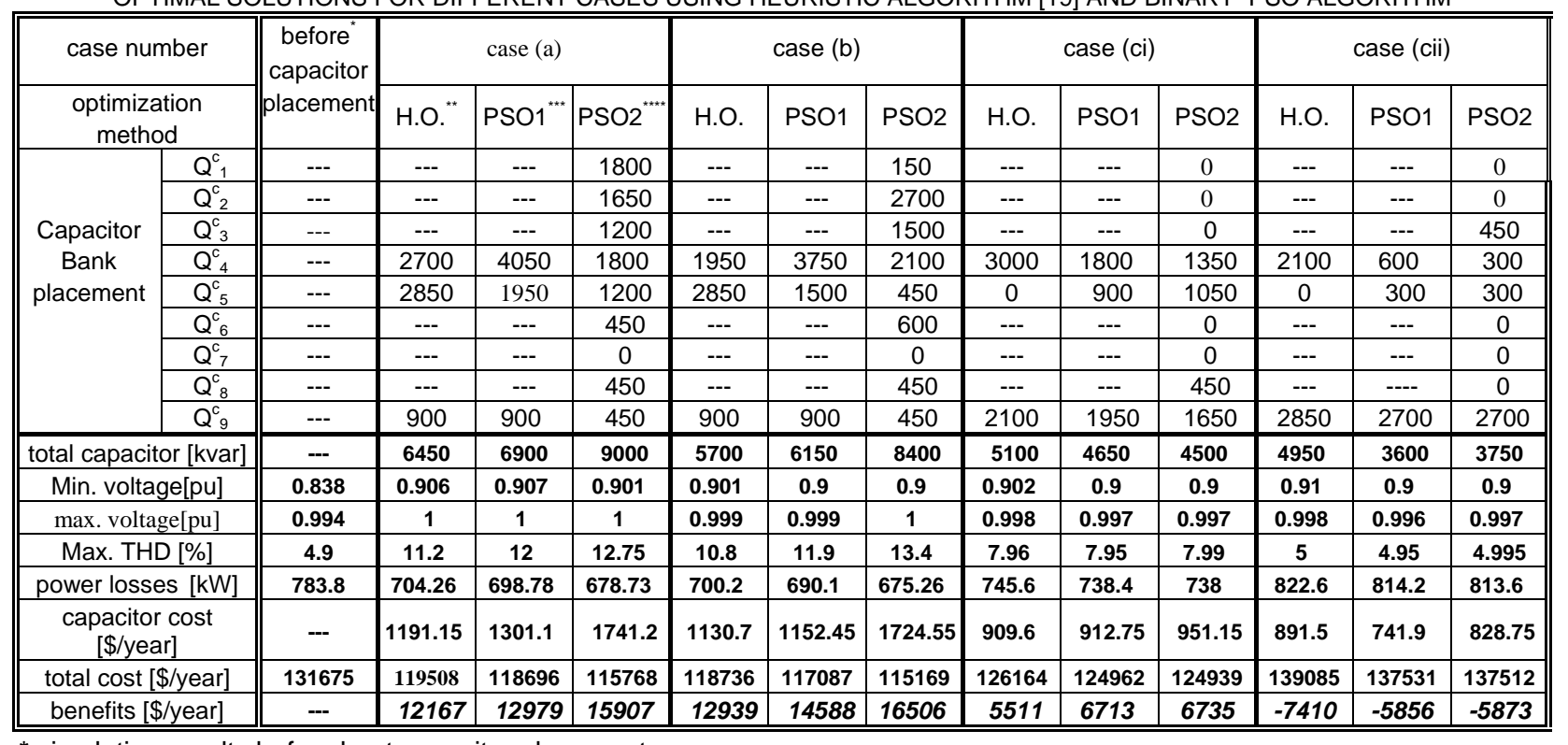

* simulation results befor shunt capacitor placement

** simulation results after heuristic optimization algorithm at a candidate buses [4, 5and 9]

*** simulation results after PSO, at a candidate buses [4, 5and 9]

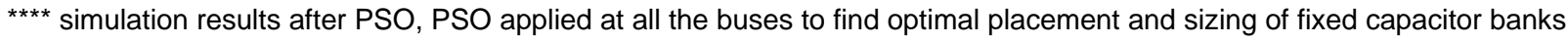

\section{CONCLUSION}

In this paper, we have proposed a binary PSO on radial distribution feeders with distorted voltage supply to determine (1) the optimal shunt capacitor sizing at a candidate buses (2) the optimal capacitor placement and sizing.

The effectiveness of the binary PSO to solve the discrete optimization problems of capacitor placement and sizing has been demonstrated through the numerical example. It was found that the optimal placement and sizing at fundamental frequency of voltage without taken into account the effect of harmonics can result unacceptable THD levels.

\section{REFERENCES}

[1] H. N. Ng, M. M. A. Salama, and A.Y. Chikhani “Classification of capacitor allocation techniques” IEEE Trans. Power Delivery, vol.15, pp387-392, Jan.2000. 
[2] G. Levitin, A. Kalyuzhny, A. Shenkman, and M.Chertkov “Optimal capacitor allocation in distribution systems using a genetic algorithm and a fast energy loss computation technique” IEEE Trans. Power Delivery, vol 15, pp.623-628, April 2000.

[3] M. Delfanti, G. P. Granelli, P. Marannino, and M. Montagna, “Optimal capacitor placement using deterministic and genetic algorithms,” IEEE Trans. Power Syst., vol. 15, pp. 1041-1046, Aug. 2000.

[4] H. N. Ng, M. M. A. Salama, and A.Y.Chikhani "Capacitor allocation by approximate reasoning: fuzzy capacitor placement” IEEE Trans. Power Delivery, vol. 15, pp. 393-398, Jan. 2000.

[5] J. C. Carlisle and A. A. El-Keib "A graph search algorithm for optimal placement of fixed and switched capacitor on radial distribution systems” IEEE Trans. Power delivery, vol. 15, pp. 423-428, Jan. 2000.

[6] J. L. Bala, P. A. Kuntz, and M. J. Pebles "Optimal capacitor allocation using a distribution-analyzerrecorder” IEEE Trans. Power Delivery, vol. 12, pp. 464-469, Jan. 1997.

[7] R. A. Gallego, A. J. Monticelli, and R. Romero, “ Optimal Capacitor Placement in Radial distribution Netwerk,” IEEE Trans. Power systems, vol. 16, pp. 630-637, Nov. 2001

[8] H. D. Chaing, J. C. Wang, J. Tong, and G. Darling,“'Optimal capacitor placement, replacement and control in large-scale unbalanced systems: system modelling and a new formulation” IEEE Trans. Power systems, vol. 10, pp. 356-362, Feb. 1995.

[9] H. D. Chaing, J. C. Wang, J. Tong, and G. Darling,“'Optimal capacitor placement, replacement and control in large-scale unbalanced systems: system solution algorithms and numerical studies” IEEE Trans. Power systems, vol. 10, pp. 356-362, Feb. 1995.

[10] Y. H. Huang, H. T. Yang, and C. L Huang, "Solving the Capacitor Placement Problem in a Radial Distribution System Using Tabu Search Approach,” IEEE Trans. Power systems, vol. 11, pp.1868-1873, Nov. 1996.

[11] C. R. Cavati, “Optimal allocation of fixed capacitors on aerial distribution systems,” Int. Journal of Power and Energy Systems, vol. 19, pp. 193-196, 1999.

[12] M. Chis, M. M. Salama and S. Jayaram, "Capacitor placement in distribution systems using heuristic search strategies,” IEE Proc.-Gener Transm. Disturb. Vol. 144, pp. 225-230, May 1997.

[13] Y.-T.Hsiao and C.-Y. Chien, "Optimisation of capacitor allocation using an interactive trade-off method," IEE Proc.-Gener Transm. Disturb. Vol. 148, pp. 371-374, July 2001.

[14] K. N. Miu, H. D. Chiang and G. Darling, "Capacitor placement, replacement and control in large-scale distribution systems by a GA-based two-stage algorithm,” IEEE Trans. Power Syst., vol. 12, pp. 11601166, Aug. 1997.

[15] S. Sundhararajan and A. Pahwa, "Optimal selection of capacitors for radial distribution systems using a genetic algorithm,” IEEE Trans. Power Systems, vol. 9, pp. 1499-1505, Aug. 1994.

[16] M. E. Baran and F. F. Wu, "Optimal sizing of capacitors placed on a radial distribution system,” IEEE Trans. Power Delivery, vol. 4, pp. 735-743, Jan. 1989.

[17] H. D. Chiang, J. C. Wang, O. Cockings, and H. D. Shin, "Optimal capacitor placements in distribution systems, part I: a new formulation and the overall problem,” IEEE Trans. Power Delivery, vol. 5, pp. 634642, Apr. 1990.

[18] H. D. Chiang, J. C. Wang, O. Cockings, and H. D. Shin,“Optimal capacitor placement in distribution systems, part II: solution algorithms and numerical results,” IEEE Trans. Power Delivery, vol. 5, pp. 643649, Apr. 1990.

[19] Y.Baghzouz and S.Ertem, "Shunt Capacitor Sizing For Radial Distribution Feeders With Distorted Substation Voltages,” IEEE Trans. Power Delivery, vol. 5, pp. 650-657, Apr. 1990.

[20] Y.Baghzouz, "Effects of nonlinear loads on optimal capacitor placement in radial feeders," IEEE Trans. Power Delivery, vol.6, pp. 245-251, Jan.1991.

[21] M. A. S. Masoum, A. Jafarian, M. Ladjevardi, E. F. Funchs, and W.M. Grady, "Fuzzy Approach for Optimal Placement and Sizing of Capacitor Banks in the Presence of Harmonics," IEEE Trans. Power Delivery, vol. 19, pp. 822-829, Apr. 2004.

[22] M. A. S. Masoum, M. Ladjevardi, A. Jafarian, and E. F. Fuchs, "Optimal Placement, Replacement and Sizing of Capacitor Banks in Distorted Distribution Networks by Genetic Algorithms,” IEEE Trans. Power Delivery, vol. 19, pp. 1794-1801, Oct. 2004.

[23] B. Gou and A. Abur, "Optimal capacitor placement for improving power quality," in Proc. Power Eng. Meeting, vol. 1, 1999, pp. 488-492.

[24] C. T. Hsu, Y. H. Yan, C. S. Chen, and S. L. Her, "Optimal reactive power planning for distribution systems with nonlinear loads,” in Proc. IEEE Region 10 Int. Conf. Computer, Communication, Control and Power Engineering, pp. 330-333, 1993.

[25] Z. Q. Wu and K. L. Lo, "Optimal choice of fixed and switched capacitors in radial distributions with distorted substation voltage,” Proc. Inst Elect. Eng., Gen., Transm. Disturb., vol. 142, no. 1, pp. 24-28, 1995. 
[26] M. A. S. Masoum, M. Ladjevardi, E. F. Fuchs, and W. M. Grady, "Optimal sizing and placement of fixed and switched capacitor banks under nonsinusoidal operating conditions,” in Proc. IEEE Summer Power Meeting, pp. 807-813, July 2002.

[27] M. A. S. Masoum, M. Ladjevardi, E. F. Fuchs, and W. M. Grady, “Application of local variations and maximum sensitivities selections for optimal placement of shunt capacitor banks under nonsinusoidal operating conditions,” in Proc. 34th Annu. North American Power Symp., pp. 507-515.

[28] J. Kennedy and R. Eberhart, "Particle swarm optimization,” in Proc.IEEE Int. Conf. Neural Networks, vol. IV, Perth, ustralia, 1995, pp. 1942-1948.

[29] Y. Shi and R. Eberhart, "Parameter selection in particle swarm optimization," in Proc. 7th Ann. Conf. Evolutionary Program., pp. 591-600, Mar. 1998.

[30] L.-P Zhang, H.-J. Yu and S.-X Hu, "Optimal choice of parameters for particle Swarm Optimization,” Journal of Zhejiang Univ. SCI. pp. 528-534. 2005 6A(6).

[31] J. F. Schutte, J. A. Reinbol, B. J. Fregly, R. T. Haftka, and A. D. George, "Parallel global optimization with the particle swarm algorithm” Int. J. Numer. Meth. Engng 2004; 61:2296-2315.

[32] X. Hu, R. Eberhart, Y. Shi, "Engineering Optimization with Particle Swarm”. Proceedings of the IEEE Swarm Intelligence Symposium, Indianapolis, pp. 53-57, 2003.

[33] K. Sedlaczek, P. Eberhard, "Optimization of Nonlinear Mechanical Systems under Constraints with the Particle Swarm Method” Proceedings of Applied Mathematics and Mechanics, 4(1), pp. 169-170, 2004.

[34] J. B. Park, K. S. Lee, J. R. Shin, and K. Y. Lee, “A Particle Swarm Optimization for Economic Dispatch With Nonsmooth Cost Functions” IEEE Trans. Power Syst., vol. 20, pp. 34-42, Feb. 2005.

[35] K. Sedlaczek and P. Eberhard, "Constrained Particle Swarm Optimization of Mechanical Systems" 6th World Congresses of Structural and Multidisciplinary Optimization Rio de Janeiro, 30 May - 03 June 2005, Brazil.

[36] H. Yoshida, K. Kawata, Y.Fukuyama, S.Takayama, and Y. Nakanishi “Aparticle swarm optimization for reactive power and voltage control considering voltage security assessment” IEEE Trans. Power Delivery, vol. 15, pp.1232-1239, Nov.2000.

[37] M. A. Abido, “Optimal design of power-system stabilizers using particle swarm optimization,” IEEE Trans. Energy Conv., vol. 17, no. 3, pp. 406-413, Sept. 2002.

[38] B. Zhao, C. X. Guo, and Y. J. Cao, “A Multiagent-Based Particle Swarm Optimization Approach for Optimal Reactive Power Dispatch” IEEE Trans. Power Syst., vol. 20, pp. 1070-1078, May. 2005.

[39] J. Kennedy and R. C. Eberhart, “A Discrete Binary Version of the Particle Swarm Algorithm,” Proc. of the conference on Systems, Man, and Cybernetics SMC97, pp.4104-4109, 1997.

[40] S. Herraiz, L. Sainz, and J. Clua, "Review of Harmonic Load Flow Formulations” IEEE Trans. Power Delivery, vol. 18, pp.1079-1087, July.2003.

[41] E. Acha and M. Madrigal, Power Systems Harmonics, John Wiley \& Sons, England, 2002. 